\section{Which women uses social Internet networks during pregnancy?}

\section{Sylvie Viaux-Savelon ${ }^{1 *}$, Catherine Fouillet ${ }^{2}$, Nicolas Bodeau ${ }^{1}$ and Jacky Nizard ${ }^{3}$}

${ }^{1}$ Department of Child and Adolescent Psychiatry, Sorbonne Universités, UPMC University Paris 06, Paris, France

${ }^{2}$ University Paris Ouest Nanterre, Paris X, France

${ }^{3}$ Department of Obstetrics and Gynaecology, Sorbonne University, UPMC University Paris 06, CNRS UMR 7222, INSERM U1150, Paris, France

\section{Abstract}

Internet has become an important part of our life, including during pregnancy where it is broadly used to find information (84\%). The aims of this study were (1) to describe the proportion of women using Internet Social Networks (ISN) concerning their pregnancy, during pre or postpartum hospital stay, (2) to define how ISN users refer to their pregnancy and delivery on these social networks, (3) to compare anxiety level, social sustain level, sociodemographic characteristics of the both population (4) and to determine profiles of the ISN users with multiple correspondence analysis.

Methods: 399 questionnaires were distributed in the postpartum wards of two academic hospitals in Paris, and 258 fully filled were retrieved. Tools: Anxiety scale (STAI- A and B), Cutrona Social Provisions Scale, sociodemographic and obstetrical questionnaire.

Results: $76 \%(n=195)$ were ISN users. We compared ISN users versus ISN non users women. Demographically, the two populations were comparable. Anxiety scores were similar in both groups, whereas social support scores showed a statistical difference in social integration.

In the global population, $84 \%$ use Internet for information concerning pregnancy; this rate is higher for ISN users than ISN non users (tendency 0.058).

ISN were used in priority for sharing with relatives, and $10 \%$ with other pregnant women. Concerning pregnancy, patients posted in priority the birth announcement $(28 \%)$, the pregnancy announcement $(23 \%)$, and the newborn's pictures (12\%). $6 \%$ posted their fetuses' ultrasound pictures.

Three clusters of ISN users were extracted with statistically different social support scores $(p=0.019)$ and comparable anxiety scores. The third one, with at risk profile, used ISN as social support. For all women, but specifically for younger and more socially fragile women, Internet gives to professional new perspectives to develop information and prevention tools during the perinatal period.
More Information

*Address for Correspondence: Dr. Sylvie Viaux-Savelon, Department of Child and Adolescent Psychiatry, Groupe Hospitalier Universitaire Pitié-Salpêtrière, 45-83, Boulevard de l'Hôpital, 75013 Paris, France, Tel: +33 142162363; Fax: +33 142162331; Email: sylvie.viaux@aphp.fr

Submitted: March 19, 2021 Approved: March 30, 2021 Published: March 31, 2021

How to cite this article: Viaux-Savelon S, Fouillet C, Bodeau N, Nizard J. Which women uses social Internet networks during pregnancy? Clin J Obstet Gynecol. 2021; 4: 025-032.

DOI: 10.29328/journal.cjog.1001082

ORCiD: orcid.org/0000-0002-4555-3499

Copyright: () 2021 Viaux-Savelon S, et al. This is an open access article distributed under the Creative Commons Attribution License, which permits unrestricted use, distribution, and reproduction in any medium, provided the original work is properly cited.

Keywords: Internet social network; Pregnancy social support; Anxiety; Prevention

(D) Check for updates

OPEN ACCESS

\section{Introduction}

In January 2016, worldwide, 3.419 billion people had an Internet access (Internet users), which represented $46 \%$ of the population. This figure has increased by $10 \%$ from January 2015, and by $21 \%$ from 2014 to 2015 [1]. 2.307 billion are active social media users, which represents $31 \%$ of the world total population. Active social media users are defined as users that were connected more than one time on a website.

In France, in January 2016, 55.43 millions (86\%) people out of 64.53 millions were active web users/Internet users, with a 7\% increase since January 2015.
Facebook was created in 2004 in Harvard University (and subsequently opened to the world in September 2006), Twitter in 2006, Instagram in 2010, and many other Internet social networks (ISN) followed.

Overall, in January 2016, 2.307 billion people worldwide (31\%) use regularly social networks (active social media users on the most active platform in each country) and 3.790 billion people via their mobile phone (unique mobile users), which represents $51 \%$, and this proportion is always growing: a $4 \%$ increase from January 2015 but a $23 \%$ increase from January 2014 to January 2015. 
In France, in January 2016, 32 million people (50\%) were active social Internet network users on Facebook, which stays the first social network used in France, in Western Europe (201 millions, 48\% of the population), and Worldwide (2.31 billion, $31 \%$ of the population). The $20-29$ year-old age range represents 29\% (higher percentage among age groups) of the global French population users (32 million), with $14 \%$ of female and $15 \%$ of male users. The $30-39$ year-old age group represents $21 \%$ of the global population, with $11 \%$ of female and $10 \%$ of male users [2].

Each day in January 2016, French ISN users spent an average of 3.37 hours connected to Internet through a computer or tablet, and 0.58 hours through a mobile phone, with a total of 1.3 hours spent on social network [2].

Concerning French data, in January 2016, 82\% of Internet users access the Internet every day and $13 \%$ at least one per week. The average daily use of ISN summed up to 2 hours, while spending on average more than three hours a day watching television. Amongst ISN, Facebook had the largest penetration with $43 \%$ of the population of users, followed by Facebook messenger (22\%), Google+ (11\%), and Twitter (11\%). [2].

Pregnant women are in the group of highest ISN users by their age range. Moreover, pregnancy is a particularly stressful period in a woman's life. Pregnancy is announced as a social event in the close network, at work, to close friends, and family. It is culturally integrated in the family and the society, who provide information and support. Although there is a growing literature focusing on Internet use for health care information [3,4] and decision making [5-7] during pregnancy, studies describing the ISN use during this particular period of life are rare [8]. These studies point out the importance for the obstetrical teams to develop digital media strategies, to do research on ISN use and to better describe profile of pregnant women using ISN in order to adapt these media strategies [9].

The aims of the current study were (1) to describe the proportion of women using ISN concerning their pregnancy, during pregnancy or the postpartum hospital stay, (2) to describe how they refer to their pregnancy and delivery on these ISN, (3) to compare anxiety level, social support level, socio-demographic characteristics of women ISN users and ISN non users, and (4) to identify specific profiles of ISN users by using multiple correspondence analysis to determine groups at risk.

\section{Methods}

\section{Population}

From April $1^{\text {st }}$ to June $30^{\text {th }} 2014$, women in the postpartum ward of two different hospitals in central Paris, France (Pitié Salpêtrière Hospital and Necker Hospital) were asked to fill questionnaires and scales (APPENDIX 1).
Exclusion criteria were major obstetrical complication, major psychiatric disorder, non-French speakers, or age below 18 years. We included all other patients.

\section{Procedure}

During this 3 months period, 399 questionnaires were delivered and 264 collected. 258 were filled and were considered exploitable, 8 were not filled with « refusal to answer ». The other women kept the questionnaires, hence they were not collected $(n=127)$ (Figure 1$)$.

\section{Tools}

Questions included general information on pregnancy, social network general use, and more specifically during pregnancy and birth (APPENDIX 1).

Two validated self-evaluation scales were included: The French versions of the Spielberger Scale, which rates State and Features of Anxiety (STAI-A; STAI B) [10-12], and the French version of the Cutrona Scale, which assesses social support $[13,14]$.

The State Anxiety Scale (STAI A) evaluates in 20 items the current state of anxiety, asking how respondents feel "right now," using items that measure subjective feelings of apprehension, tension, nervousness, worry, and activation/ arousal of the autonomic nervous system. The Trait Anxiety Scale (STAI - B) evaluates in 20 items relatively stable aspects of "anxiety proneness," including general states of calmness, confidence, and security.

The Cutrona Scale contains 24 items, four for each of the following dimensions of social support: Attachment (a sense of emotional closeness and security), Social Integration (a sense of belonging to a group of people, who share common interests and recreational activities), Reassurance of Worth (recognition of one's competence or skills), Reliable Alliance (assurance that others can be counted on for tangible assistance), Guidance (advice or information), and Opportunity for Nurturance (providing assistance to others).

\section{Ethical statement}

The local Ethical Committee (CPPIDF6) approved the study. Questionnaires and scales were given to the patients with an oral explanation on the study, completed by a letter summarizing the given information. Written informed consent was obtained from all participants and the study was conducted in accordance with the Declaration of Helsinki.

All documents were collected at hospital discharge.

\section{Statistics}

Data analysis was carried out using the R software, version 2.10. To compare the 2 groups we used Fisher's exact test for qualitative variables and Student Test for quantitative variables with Welch's correction for unequal variances. Secondarily, a multiple correspondence analysis (MCA) was 
performed for the ISN users group followed by a clustering to determine profiles of ISN users. The significance level of the statistical tests was set $<0.05$.

\section{Results}

Out of the 399 questionnaires distributed to eligible patients, 258 were retrieved (Figure 1). Of these, 76\% $(n=195)$ were ISN users. We compared ISN users versus ISN non users women. The two populations were comparable concerning socio demographic characteristics (age, obstetrical complications, family and working status, education level and pregnancy preparation). They differed on Internet use concerning pregnancy information that was higher for ISN users than ISN non users (tendency odds $=0.47$ [0.22-1.02], $p=0.058)$ (Table 1).

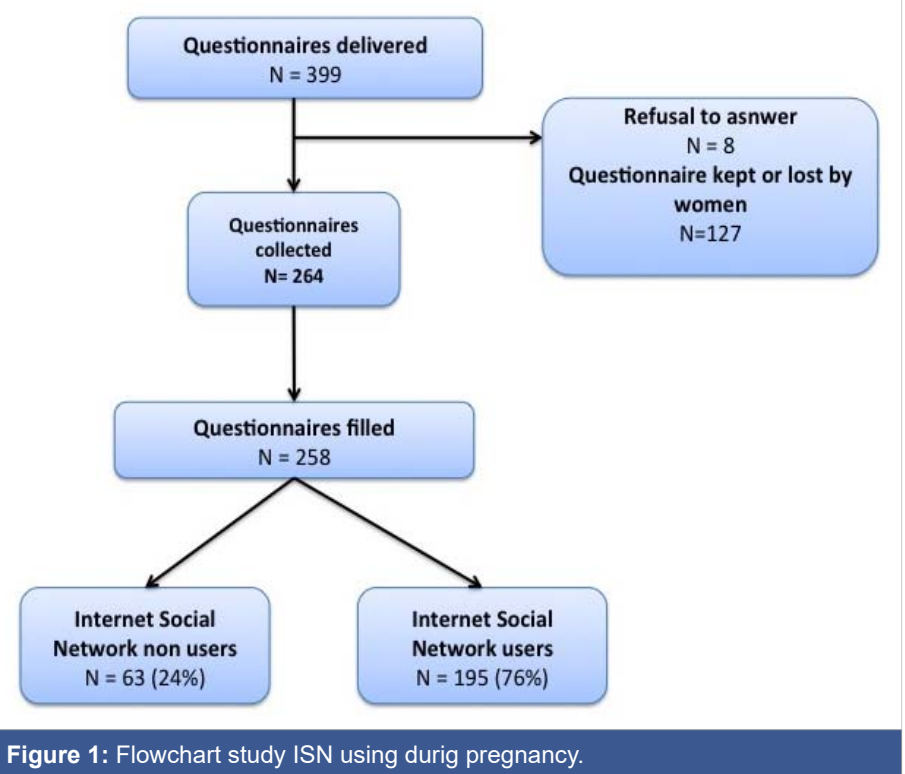

Anxiety score results were similar in both groups, whereas social support scores showed a statistical difference in social integration score which was higher for ISN users $(t=-2.21$, $p=0.037$ ) (Table 2).

When specifically analyzing the ISN user population, only $2 \%$ were using a network other than Facebook $(83 \%)$ or Twitter (15\%), with other members of their ISN being mostly close friends and family. As a consequence, less that $25 \%$ of their ISN members were people they didn't know outside the network (Table 3A). Almost half the patients accessed their ISN every day, which was close to what their partners do.

The ISN were used in priority to share with relatives or close friends, and only in $10 \%$ with other pregnant women (Table 3A). When posting information concerning pregnancy on their ISN, patients posted in priority the birth announcement (28\%), the pregnancy announcement (23\%), selfish of themselves pregnant (16\%), and pictures of the newborn $(12 \%)$. Six percent of these patients posted ultrasound images of their fetus (Table 3B).

Most patients got support from their partner, their family, and their friends during pregnancy. Similarly, most patients declared exchanging with other pregnant women within the family or friends and colleagues outside of ISN (Table 3C).

The multiple correspondence analysis (MCA) performed for the ISN users group, using demographic data and ISN use, identified three groups (Figure 2 and APPENDIX 2). These three clusters had statistically different social support scores (Kruskal-Wallis $\mathrm{X}^{2}=7,934, p=0.019$ ) with comparable anxiety scores (Table 4).

\section{Characteristics of the clusters}

In cluster $1(n=61)$, women were 25-34 years old, with

Table 1: Population characteristics comparison of women users and no users of internet social network.

\begin{tabular}{|c|c|c|c|c|c|}
\hline & & \multicolumn{2}{|c|}{ Internet social network } & \multirow[b]{3}{*}{ odds [ $95 \%$ conf. int] } & \multirow[b]{3}{*}{$p$ value } \\
\hline & & non users & users & & \\
\hline & & $n(\%)$ & $n(\%)$ & & \\
\hline \multirow{3}{*}{ Age range $(y)$} & $18-24$ & $5(8 \%)$ & $24(12 \%)$ & & 0,100 \\
\hline & $25-34$ & $35(56 \%)$ & $126(65 \%)$ & & \\
\hline & $>34$ & $23(37 \%)$ & $44(23 \%)$ & & \\
\hline \multirow{2}{*}{ Pregnancy } & with organic complications & $21(34 \%)$ & $61(32 \%)$ & $1.09[0.56-2.08]$ & 0,892 \\
\hline & none organic complication & $41(66 \%)$ & $130(68 \%)$ & & \\
\hline \multirow{2}{*}{ Family status } & alone & $5(8 \%)$ & $19(10 \%)$ & $0.8[0.22-2.35]$ & 0,885 \\
\hline & in couple & $58(92 \%)$ & $176(90 \%)$ & & \\
\hline \multirow{3}{*}{ Working status } & work & $2(3 \%)$ & $17(9 \%)$ & & 0,378 \\
\hline & no working & $13(21 \%)$ & $36(18 \%)$ & & \\
\hline & vacancies & $48(76 \%)$ & $142(73 \%)$ & & \\
\hline \multirow{2}{*}{ First pregnancy } & no & $36(57 \%)$ & $88(45 \%)$ & $1.6[0.87-2.98]$ & 0,139 \\
\hline & yes & $27(43 \%)$ & $106(55 \%)$ & & \\
\hline \multirow{2}{*}{ Study level } & undergraduate & $17(27 \%)$ & $37(19 \%)$ & $1.59[0.76-3.22]$ & 0,231 \\
\hline & post graduate & $45(73 \%)$ & $156(81 \%)$ & & \\
\hline \multirow{2}{*}{ Pregnancy preparation } & yes & $25(40 \%)$ & $97(51 \%)$ & $0.66[0.35-1.23]$ & 0,210 \\
\hline & no & $37(60 \%)$ & $95(49 \%)$ & & \\
\hline \multirow{2}{*}{ Using internet concerning pregnancy information } & yes & $47(75 \%)$ & $168(86 \%)$ & $0.47[0.22-1.02]$ & $0,058^{*}$ \\
\hline & no & $16(25 \%)$ & $27(14 \%)$ & & \\
\hline
\end{tabular}


Table 2: Anxiety and social support scales comparison scores in the population of women users and no users of internet social network.

\begin{tabular}{|c|c|c|c|c|c|c|}
\hline & \multicolumn{4}{|c|}{ Internet social network } & \multirow[b]{3}{*}{$t$} & \multirow[b]{3}{*}{$p$ value } \\
\hline & \multicolumn{2}{|c|}{ non users } & \multicolumn{2}{|c|}{ users } & & \\
\hline & $\mathbf{N}$ & mean $\pm \mathrm{sd}$ & $\mathbf{N}$ & mean \pm sd & & \\
\hline \multicolumn{7}{|l|}{ Anxiety scales scores } \\
\hline STAI. Anxiety Status & 57 & $34.1 \pm 10.5$ & 176 & $33 \pm 8.9$ & 0,748 & 0,455 \\
\hline STAI. AnxietyFeatures & 58 & $35.6 \pm 8.9$ & 168 & $35 \pm 8.3$ & 0,468 & 0,640 \\
\hline \multicolumn{7}{|c|}{ Social support Cutrona component scores } \\
\hline Guidance & 58 & $14 \pm 2.4$ & 163 & $14.5 \pm 1.9$ & $-1,439$ & 0,154 \\
\hline Reassurance of Worth & 58 & $13.1 \pm 2.6$ & 163 & $13.6 \pm 2$ & $-1,315$ & 0,192 \\
\hline Social Integration & 58 & $13.3 \pm 2.4$ & 163 & $14 \pm 1.6$ & $-2,121$ & $0,037^{*}$ \\
\hline Attachment & 58 & $13.9 \pm 2.5$ & 163 & $14.5 \pm 2$ & $-1,729$ & 0,087 \\
\hline Nurturance & 58 & $13.3 \pm 2.7$ & 163 & $13.7 \pm 2$ & $-0,960$ & 0,340 \\
\hline Reliable Alliance & 58 & $14 \pm 2.4$ & 163 & $14.7 \pm 1.9$ & $-1,818$ & 0,073 \\
\hline Total social support score & 60 & $79 \pm 19.2$ & 174 & $79.7 \pm 22.3$ & $-0,219$ & 0,827 \\
\hline
\end{tabular}

Table 3A: How women use Internet social network (ISN).

\begin{tabular}{|c|c|c|}
\hline Using ISN characteristics & & $n(\%)$ \\
\hline \multicolumn{3}{|c|}{ Internet use for information on pregnancy } \\
\hline & yes & $168(86 \%)$ \\
\hline & no & $27(14 \%)$ \\
\hline & Face book & $162(83 \%)$ \\
\hline & Twitter & $30(15 \%)$ \\
\hline & others (blog) & $3(2 \%)$ \\
\hline & Facebook & $108(62 \%)$ \\
\hline & twitter & $28(16 \%)$ \\
\hline & others & $4(2 \%)$ \\
\hline & no internet social network & $35(20 \%)$ \\
\hline \multicolumn{3}{|c|}{ Why did you use ISN for pregnancy? } \\
\hline & Share the event with relatives/close friends & $68(35 \%)$ \\
\hline & up to $25 \%$ & $21(11 \%)$ \\
\hline & $25-50 \%$ & $34(18 \%)$ \\
\hline & $50-75 \%$ & $84(46 \%)$ \\
\hline & $75-100 \%$ & $45(24 \%)$ \\
\hline \multicolumn{3}{|l|}{ People only known within ISN } \\
\hline & up to $25 \%$ & $84(62 \%)$ \\
\hline & $25-50 \%$ & $32(24 \%)$ \\
\hline & $50-75 \%$ & $17(13 \%)$ \\
\hline & $75-100 \%$ & $2(1 \%)$ \\
\hline \multicolumn{3}{|l|}{ Access frequency } \\
\hline \multicolumn{3}{|l|}{ Access frequency of patient } \\
\hline & every day & $65(41 \%)$ \\
\hline & less than once a day & $24(15 \%)$ \\
\hline & 1 or 2 times a week & $26(16 \%)$ \\
\hline & once a month & $7(4 \%)$ \\
\hline & less than once a month & $19(12 \%)$ \\
\hline & don't know & $19(12 \%)$ \\
\hline
\end{tabular}




\begin{tabular}{|c|c|}
\hline \multicolumn{2}{|l|}{ Information posted on ISN } \\
\hline \multicolumn{2}{|l|}{ Concerning pregnancy by patient } \\
\hline yes & $74(39 \%)$ \\
\hline no & $117(61 \%)$ \\
\hline \multicolumn{2}{|l|}{ Concerning pregnancy by partner } \\
\hline yes & $27(17 \%)$ \\
\hline no & $135(83 \%)$ \\
\hline Don't know & $1(1 \%)$ \\
\hline \multicolumn{2}{|c|}{ Specific use of ISN during pregnancy } \\
\hline Pregnancy announcement & $44(23 \%)$ \\
\hline Selfie during pregnancy & $32(16 \%)$ \\
\hline Baby's pictures posted & $23(12 \%)$ \\
\hline Information posted on pregnancy progression & $12(6 \%)$ \\
\hline Fetal ultrasound image & $11(6 \%)$ \\
\hline \multicolumn{2}{|l|}{ Concerning birth by patient } \\
\hline yes & $53(28 \%)$ \\
\hline no & $138(72 \%)$ \\
\hline \multicolumn{2}{|l|}{ Concerning birth by partner } \\
\hline yes & $34(20 \%)$ \\
\hline no & $132(80 \%)$ \\
\hline \multicolumn{2}{|l|}{ If birth is posted on ISN } \\
\hline with baby picture & $32(51 \%)$ \\
\hline without baby picture & $31(49 \%)$ \\
\hline \multicolumn{2}{|l|}{ If birth is non posted on ISN, they: } \\
\hline will not do it & $53(72 \%)$ \\
\hline will send a post later & $18(24 \%)$ \\
\hline
\end{tabular}

Table 3C: Social support of the population during pregnancy.

\begin{tabular}{|c|c|c|}
\hline Social support during pregnancy & & \\
\hline \multicolumn{3}{|l|}{ Is the partner involved in the pregnancy } \\
\hline & Totally disagree & $4(2 \%)$ \\
\hline & Disagree & $4(2 \%)$ \\
\hline & Agree & $48(25 \%)$ \\
\hline & Totally agree & $131(69 \%)$ \\
\hline & Don't know & $4(2 \%)$ \\
\hline \multicolumn{3}{|l|}{ Is the family supportive during pregnancy } \\
\hline & Totally disagree & $1(1 \%)$ \\
\hline & Disagree & $49(26 \%)$ \\
\hline & Agree & $131(69 \%)$ \\
\hline & Totally agree & $8(4 \%)$ \\
\hline & Don't know & $0(0 \%)$ \\
\hline \multicolumn{3}{|l|}{ Are friends supportive during pregnancy } \\
\hline & Totally disagree & $2(1 \%)$ \\
\hline & Disagree & $1(1 \%)$ \\
\hline & Agree & $62(34 \%)$ \\
\hline & Totally agree & $108(60 \%)$ \\
\hline & Don't know & $7(4 \%)$ \\
\hline \multicolumn{3}{|l|}{$\begin{array}{l}\text { Exchange with others pregnant women or } \\
\text { couples }\end{array}$} \\
\hline & No & $16(8 \%)$ \\
\hline & Within the family & $126(65 \%)$ \\
\hline & $\begin{array}{l}\text { With friends/ } \\
\text { colleagues }\end{array}$ & $136(70 \%)$ \\
\hline & Within social network & $26(13 \%)$ \\
\hline
\end{tabular}

college education level, used ISN every day but didn't share information concerning pregnancy and didn't chat with their close friends or others pregnant women on ISN. They didn't post announcement of birth and had possibilities to share information concerning their pregnancy with their friends outside of ISN. In the same way, their partners didn't post any announcement or information concerning the pregnancy on ISN. Overall, these women and their partners had an ISN account but communicated on their pregnancy offline with their close friends and family.

In the cluster $2(n=41)$, women were 25-34 years old; they shared information concerning their pregnancy and posted announcements of birth on ISN, shared with their close friends on ISN, even if they could share with their friends concerning their pregnancy outside of Internet. In the same way, their partner had ISN account and share information concerning pregnancy and post birth's announcement on ISN in the same way. Overall, these women and their partners were very communicative both offline and on ISN.

In the cluster $3(n=24)$, women were 18-24 years old; single, with low education level and no work. They didn't share offline with people concerning their pregnancy and shared on ISN with other pregnant women. They were not taking part in pregnancy preparation courses proposed in the hospital where they could meet other pregnant women. Their total social support score was significantly lower than in the other cluster (score $=72.1$, Kruskal-Wallis $\mathrm{X}^{2}=7,934$, $p=0.019$ ) below the threshold (Table 4).

\section{Discussion}

In our population, $84 \%$ of the women used Internet to get information on pregnancy. Regardless of the wide and recent spreading of ISN, this proportion is consistent with a earlier study (83,3\%) performed in France in 2009 [15] but smaller than in other developed country, with $95 \%$ in the O'Higgins study [8]. We have to consider that ISN users answered probably more likely to the study than ISN non users, which can be a selection bias. Nevertheless, in our population, Internet use for information on pregnancy was more frequent in ISN users $(86 \%)$ than in no ISN users $(75 \%)$ (odds $=0.47[0.22$ 1.02], $p=.058$ ). Nulliparous women were not significantly higher in this group (45\%), but that was consistent with the O'Higgins study (Table 1). When using ISN, pregnant women announced their pregnancy (23\%), posted selfies (16\%), posted babies pictures $(12 \%)$, posted fetal ultrasound images (6\%) or exchanged with their network, which is essentially

Table 4: Anxiety score and Cutrona support score comparison in the 3 cluster.

\begin{tabular}{|c|c|c|c|c|c|c|c|c|c|c|c|}
\hline & \multicolumn{3}{|c|}{ Cluster 1} & \multicolumn{3}{|c|}{ Cluster 2} & \multicolumn{3}{|c|}{ Cluster 3} & \multirow[b]{2}{*}{ Kruskal-Waliis } & \multirow[b]{2}{*}{$p$ value } \\
\hline & $\mathrm{N}$ & mean & sd & $\mathrm{N}$ & mean & sd & $\mathrm{N}$ & mean & sd & & \\
\hline STAI.a & 58 & 33,5 & 9,7 & 37 & 34,2 & 9,1 & 20 & 32,5 & 10,1 & 0.683 & 0,711 \\
\hline STAI.b & 57 & 33,2 & 7,4 & 38 & 37,1 & 9,7 & 20 & 36,5 & 9 & 4,685 & 0,096 \\
\hline Social support cutrona total score & 58 & 81,6 & 23,2 & 39 & 83,5 & 15,4 & 22 & 72,1 & 26,3 & 7,934 & 0,019 \\
\hline
\end{tabular}




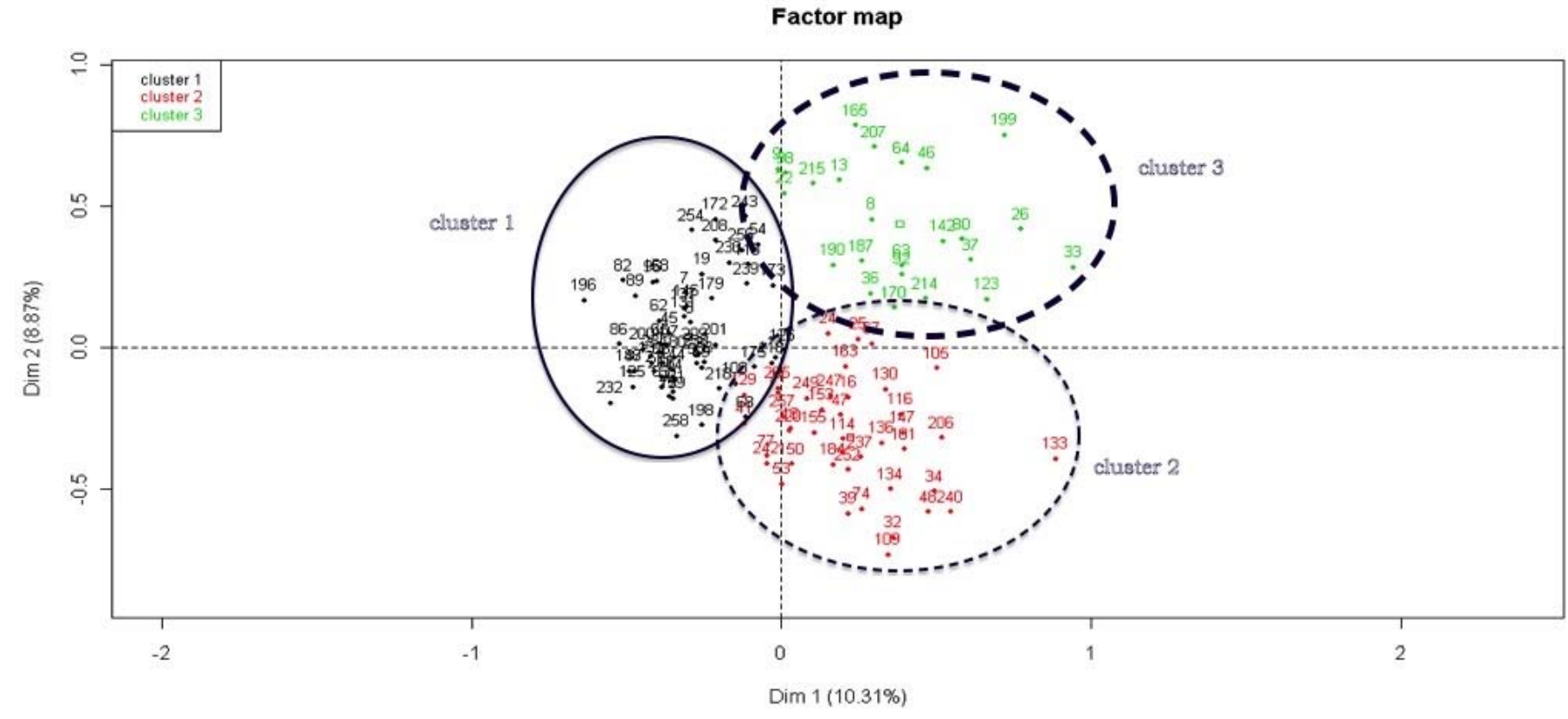

Figure 2

composed of their family or close friends (Table 3AB). Social integration score is higher in the ISN users population, which means that the ISN users feel stronger to belong to a group of people who share common interests and recreational activities than no ISN users. The clustering of our population in three confirmed this result. Women in cluster 3, with more fragility and loneliness, seem to use ISN as social support and space to share with others women. This result is in line with other studies [8] that point out that women who were socially disadvantaged reported high levels of digital media use. Further studies should be performed about these women with little real social support to determine the possibility to improve their mood with digital applications.

To our knowledge, this is the first specific report on the use of ISN during pregnancy. We used validated questionnaires and scales to evaluate emotional states and social support of these women. Nevertheless, our study has some limits. Our population is not representative of the whole French population, with $76 \%$ of our population being users of cyber social network versus $45 \%$ in the French general population. These women were mostly from an urban environment of a large European city, and we only collected data from women who agreed to fill the questionnaire, which can explain the overall low anxiety score of the population.

Internet and ISN take an increasing place in our life and social network. Digital medical applications are growing in medical practice to improve prevention, information, treatment and its compliance, as reported in chronic diseases such as asthma or nutrition program [16-18]. Pregnant women are in the higher range of ISN users and spontaneously search medical information on Internet $[3,4]$. This Internet use is seriously assessed to develop information on decisionmaking during this period [5-7]. Yet, young and lonely women, described as the most exposed to somatic and mental disease during the perinatal period $[19,20]$ are important ISN users [8]. The ISN use of this group (cluster 3), difficult to engage in classical health care programs, could be an interesting media for screening and prevention in this population.

Moreover, our data show an overall important supportive social network for women using ISN in all three clusters. ISN seems to provide a good and supportive social network, according to its function in narcissism described by Riviere [21]. This supportive effect of ISN for pregnant women is underlined in focus group study [9] where women revealed the importance of using digital media for establishing and maintaining social connections and intimate relationships with others mothers. This is supported by Prescott, et al. results [4] who describe that pregnant women found reassurance from the experiences of others and that this reassurance resulted in them feeling less alone, as well as enabling them to normalize any symptoms or experiences they were undergoing. Accordingly, cluster 3 illustrates this use of ISN to sustain their fragility, loneliness and anxiety and to be recognized as pregnant women by the ISN community. This information could be considered during antenatal care to create ISN community of pregnant women attached to a clinic or a hospital for example.

Concerning the information posted by women, the announcement of the pregnancy on ISN for women can be considered as an acting out. The pregnancy becomes more « real » because it is posted and recognized by the community [22]. On the other side, the web community, by their comments 
and posts, help the woman to elaborate her new status. Indeed, the ISN gives to the woman a reflective mirror of her pregnancy that could be considered as the alpha function described by Bion [23] and help them support the psychic movements that they have to integrate during pregnancy [24]. Now, et al. found one quarter of fetuses « existing " on Internet before birth by pictures posted by their mothers [25]. Our data shows only $6 \%$ of ultrasound images of their fetuses posted on ISN. This phenomenon seems to be specific of a particular population with personality disorder and a lack of social support [26] and should be explored by further studies.

\section{Conclusion}

Internet has become an important part of our life, including during pregnancy where it is broadly used to find information (84\%). The ISN is a specific part of this phenomenon and particularly as a new tool of communication within our social group. Dividing our population in clusters, we identified different populations: those who have an offline social support (friends and family), who expose information on their pregnancy on the ISN, and those, more socially fragile and younger, for whom ISN provide a major social support. For all women, but more specifically for this last group, Internet gives to professional new perspectives to develop information and prevention tools during the perinatal period.

\section{Ethical approva}

All procedures performed in studies involving human participants were in accordance with the ethical standards of the national research committee and with the 1964 Helsinki declaration and its later amendments or comparable ethical standards. The local Ethical Committee (CPPIDF6) approved the study.

Informed consent: Informed consent was obtained from all individual participants included in the study.

\section{References}

1. Coeffe T. L'usage d'Internet, du mobile et des réseaux sociaux dans 232 pays (dont la France). 2016.

2. Yee W. We are social. 2016. www.fr.slideshare.net/wearesocial.sg/ digital-in-2016.

3. Sayakhot $P$, Carolan-Olah $M$. Internet use by pregnant women seeking pregnancy-related information: a systematic review. BMC Pregnancy Childbirth. 2016; 28; 16: 65.

PubMed: https://pubmed.ncbi.nlm.nih.gov/27021727/

4. Prescott J, Mackie L. "You Sort of Go Down a Rabbit Hole...You're Just Going to Keep on Searching": A Qualitative Study of Searching Online for Pregnancy-Related Information During Pregnancy. J Med Internet Res. 2017; 19: e194.

PubMed: https://pubmed.ncbi.nlm.nih.gov/28583906/

5. Lagan BM, Sinclair M, Kernohan WG. Internet use in pregnancy informs women's decision making: a web-based survey. Birth. 2010 37: 106-115.

PubMed: https://pubmed.ncbi.nlm.nih.gov/20557533/

6. Lagan BM, Sinclair M, Kernohan WG. What is the impact of the Internet on decision-making in pregnancy? A global study. Birth. 2011; 38: 336-345. PubMed: https://pubmed.ncbi.nlm.nih.gov/22112334/
7. Konheim-Kalkstein YL, Whyte R, Miron-Shatz T, Stellmack MA. What are VBAC Women Seeking and Sharing? A Content Analysis of Online Discussion Boards. Birth. 2015; 42: 277-282.

PubMed: https://pubmed.ncbi.nlm.nih.gov/26032668/

8. O'Higgins A, Murphy OC, Egan A, Mullaney L, Sheehan S, et al. The use of digital media by women using the maternity services in a developed country. Ir Med J. 2014; 107: 313-315.

PubMed: https://pubmed.ncbi.nlm.nih.gov/25556255/

9. Lupton D. The use and value of digital media for information about pregnancy and early motherhood: a focus group study. BMC Pregnancy Childbirth. 2016; 16: 171

PubMed: https://pubmed.ncbi.nlm.nih.gov/27435182/

10. Gauthier J, Bouchard S. A French-Canadian adaptation of the revised version of Spielberger's State-Trait Anxiety Inventory. Canadian J Behav Sci. 1993.

11. Julian L. Measures of Anxiety. State-Trait Anxiety Inventory (STAI), Beck Anxiety Inventory (BAl), and Hospital Anxiety and Depression Scale-Anxiety (HADS-A). Arthritis Care Res. 2011; 63: S467-S472. PubMed: https://pubmed.ncbi.nlm.nih.gov/22588767/

12. Spielberger $C$. State-Trait Anxiety Inventory. Consulting Psychologists Press, Palo Alto (CA). 1983.

13. Caron J, Tremblay M. The scale of social provisions: their validation in Quebec. 1996; 21: 158-180.

PubMed: https://pubmed.ncbi.nlm.nih.gov/9052268/

14. Russell D, Peplau LA, Cutrona CE. The revised UCLA Loneliness Scale: concurrent and discriminant validity evidence J Pers Soc Psychol. 1980; 39: 472-480.

PubMed: https://pubmed.ncbi.nlm.nih.gov/7431205/

15. Leune AS, Nizard J. Doctor Google: Use of Internet during pregnancy in France in 2009.. 2012; 41: 243-254.

PubMed: https://pubmed.ncbi.nlm.nih.gov/22236487/

16. Koufopoulos JT, Conner MT, Gardner PH, Kellar I. A Web-Based and Mobile Health Social Support Intervention to Promote Adherence to Inhaled Asthma Medications: Randomized Controlled Trial J Med Internet Res. 2016; 18: e122.

PubMed: https://pubmed.ncbi.nlm.nih.gov/27298211/

17. Tapper K, Jiga-Boy G, Maio GR, Haddock G, Lewis M. Development and preliminary evaluation of an internet-based healthy eating program: randomized controlled trial. J Med Internet Res.2 014; 16: e231. PubMed: https://pubmed.ncbi.nlm.nih.gov/25305376/

18. Zimmer B, Moessner M, Wolf M, Minarik C, Kindermann S, et al. Effectiveness of an Internet-based preparation for psychosomatic treatment: Results of a controlled observational study. J Psychosom Res. 2015; 79: 399-403.

PubMed: https://pubmed.ncbi.nlm.nih.gov/26526315/

19. Knight M, Tuffnell D, Kenyon S, Shakespeare J, Gray R, et al. Saving Lives, Improving Mothers' Care - Surveillance of maternal deaths in the UK 2011-13 and lessons learned to inform maternity care from the UK and Ireland Confidential Enquiries into Maternal Deaths and Morbidity 2009-13. National Perinatal Epidemiology Unit, University of Oxford, Oxford. 2015.

20. Tubach F, Greacen T, Saias T, Dugravier R, Guedeney N, et al. A home-visiting intervention targeting determinants of infant mental health: the study protocol for the CAPEDP randomized controlled trial in France. BMC Public Health. 2012; 12: 648. PubMed: https://pubmed.ncbi.nlm.nih.gov/22888979/

21. Riviere $\mathrm{C}$. Le lien de dépendance addictive à Internet, une nouvelle forme d'addiction? OMNSH. 2006; 10: 66.

22. Tisseron $\mathrm{S}$. Doctors and the benefits and dangers of social networks. Rev Med Suisse. 2015; 11: 1082-1084.

PubMed: https://pubmed.ncbi.nlm.nih.gov/26118232/

23. Bion WR. Aux sources de l'expérience. PUF, PARIS. 2003. 
24. Bernard-Chatelain C. L'e-baby, l'e-mother et le forum de maman blues. Spirale 4. 2011.

25. Now R. Naissance numérique: bienvenue dans le monde d'internet. Selon une étude d'AVG, un quart des enfants sont présents sur internet bien avant leur naissance. 2010.

26. Viaux-Savelon S. La parentalité échographique. Dialogue. 2013; 1: 19-31.

27. Gelaye B, Kajeepeta S, Williams MA. Suicidal ideation in pregnancy: an epidemiologic review. Arch Womens Ment Health. 2016; 19: 741-751. PubMed: https://pubmed.ncbi.nlm.nih.gov/27324912/
28. Mehdizadeh S. Self-presentation 2.0: narcissism and self-esteem on Facebook Cyberpsychol Behav Soc Netw. 2010; 13: 357-364.

PubMed: https://pubmed.ncbi.nlm.nih.gov/20712493/

29. Prizant-Passal S, Shechner T, Aderka IM. Social anxiety and internet use-A meta-analysis: What do we know? What are we missing? Computers in Human Behavior. 2016; 62: 221-229.

30. Tebeka S, Le Strat $Y$, Dubertret C. Developmental trajectories of pregnant and postpartum depression in an epidemiologic survey. $\mathrm{J}$ Affect Disord. 2016; 203: 62-68.

PubMed: https://pubmed.ncbi.nlm.nih.gov/27280964/ 